Tatiane Guimarães Pereira ${ }^{a}$

(iD) https://orcid.org/0000-0003-2928-293X

Alberto Olavo Advíncula Reis ${ }^{\mathrm{a}}$

(D) http://orcid.org/0000-0002-8880-1181

Fabiola Zionia

(iD) https://orcid.org/0000-0002-5594-4696

aniversidade de São Paulo (USP),

Faculdade de Saúde Pública,

Departamento de Saúde, Ciclos de Vida

e Sociedade. São Paulo, SP, Brasil.

Contato:

Alberto Olavo Advíncula Reis

E-mail:

albereis@usp.br

Os autores declaram que o trabalho não foi subvencionado e que não há conflitos de interesses.

Trabalho baseado na dissertação de mestrado de Tatiane Guimarães Pereira, intitulada Atitudes e intervenções de profissionais que atuam junto a mulheres grávidas ou com bebês em contexto prisional, defendida em 2015 no Programa de Pós-graduação em Saúde Pública da Universidade de São Paulo (USP).
Recebido: 20/09/2019

Revisado: 31/03/2020

Aprovado: 23/04/2020

\section{Pensar, sentir e agir de profissionais que atuam com gestantes e mães com bebês no sistema prisional}

\author{
The way of thinking, feeling and acting of professionals \\ who deal with pregnant women and mothers with \\ babies in penal institutions
}

\section{Resumo}

Introdução: a maternidade no contexto prisional assume especial complexidade devido aos efeitos psicossociais do aprisionamento, que repercutem nas mães prisioneiras e nos profissionais que atuam no meio. Objetivo: identificar formas de pensar, sentir e agir de profissionais que trabalham em contexto prisional com prisioneiras gestantes e com bebês. Métodos: pesquisa qualitativa, com uso de entrevistas com profissionais que atuavam em unidades prisionais maternoinfantis do estado de São Paulo. A coleta dos dados ocorreu em 2015. Os discursos foram submetidos à análise de conteúdo com categorização temática. Utilizou-se Winnicott e Krech como referenciais teóricos. Resultados: a análise dos discursos revelou que os profissionais precisam lidar com as limitações institucionais e as vulnerabilidades sociais das presas. Nesse contexto, atuam com base em ideias fundamentadas nas áreas em que trabalham, como as esferas sociais, jurídicas e religiosas, e são movidos por ideais contraditórios, pautados pelos direitos humanos e pela rigidez prisional da segurança, próxima da lógica da punição. Reuniões multiprofissionais para reflexões críticas potencializam o enfrentamento das adversidades. Conclusão: o compartilhamento coletivo de impotências e de potencialidades parece possibilitar novas reconfigurações do trabalho e edificar uma atuação interdisciplinar para o enfrentamento dos efeitos institucionais e psicossociais do aprisionamento.

Palavras-chave: estabelecimentos correcionais; população privada de liberdade; maternidade; trabalhador; saúde do trabalhador.

\begin{abstract}
Introduction: the motherhood experience in prison involves a unique complexity due to psychosocial effects of imprisonment, which rebound in both the incarcerated mothers and professionals working in the prison system. Objective: to identify the ways of thinking, feeling, and acting of the professionals who deal with pregnant women and mothers with babies in prisons. Methods: qualitative research conducted in 2015 with data obtained by interviews with professionals who worked for prison units in the state of São Paulo. Data underwent thematic content analysis, based on Winnicott's and Krech's studies. Results: the analysis revealed that those professionals need to deal with institutional limitations and inmates' social vulnerabilities. They relied on notions from their own working field, such as the social, legal, and religious spheres. Moreover, the professionals are driven by contradictory ideals grounded on human rights and on prison rigidity, which comes near to the punishment logic. Multidisciplinary meetings for critical reflections help overcoming these adversities. Conclusion: the collective sharing of helplessness and potentialities seems to enable new working reconfigurations and build an interdisciplinary action to face imprisonment institutional and psychosocial effects.
\end{abstract}

Keywords: correctional institutions; prisoners; motherhood; worker; occupational health. 


\section{Introdução}

Para compreensão sobre o exercício profissional de áreas variadas (saúde, jurídica, segurança, social) nas prisões, faz-se necessário analisar a dinâmica prisional, seus aspectos sociais e seus efeitos em todos os sujeitos pertencentes a esse contexto. O contexto prisional é a rede viva composta por variados grupos que nele interagem, muitas vezes compostos por sujeitos do mesmo contexto social, mas separados entre aqueles que romperam com as leis e aqueles que as representam ${ }^{1}$.

Hoje, há um aumento do encarceramento no Brasil e no mundo ${ }^{1-3} \mathrm{e}$, consequentemente, um crescimento da atuação de profissionais diretamente ${ }^{4,5}$ ligados ao contexto prisional, bem como de uma rede que se instala articulando os destinos de familiares, juristas, vizinhos, amigos, voluntários, pesquisadores e jornalistas, entre outros agentes ${ }^{6}$. Cada agente social envolvido, com um objetivo a cumprir, circula pelos portões prisionais internos e externos e assume um intermédio entre os mundos intra e extramuros, de modo que se incluem no contexto por meio de discursos e reflexões sobre o modo de funcionamento da prisão ${ }^{7}$. Todos que ali circulam passam por um processo de prisionização, ou seja, uma adoção, em maior ou menor grau, do modo de pensar, dos costumes e das regras desse contexto prisional ${ }^{8}$, cuja organização afeta radicalmente a vida psíquica e social dos apenados.

As pessoas privadas de liberdade podem sofrer efeitos emocionais, como dificuldade em projetar sua vida, baixas perspectivas de futuro, sentimento de inferioridade e manifestações de dependência de outras pessoas e de busca de proteção ${ }^{9}$. Já os profissionais que atuam nesse contexto, embora tenham garantia de sua liberdade preservada, também sofrem alguns efeitos por viverem rotineiramente na prisão. No entanto, há diferenças marcantes vividas e exercidas por esses trabalhadores. Além disso, o modo de subjetivar, expresso pela busca de recursos psíquicos e sociais de qualquer indivíduo, seja apenado ou profissional, é único. Nesse sentido, resguardadas as devidas especificidades de cada grupo, isto é, grupo de presos ou de profissionais, é inegável o sofrimento de quem se encontra no ambiente prisional. Imersos nessa dinâmica, os profissionais apresentam sofrimento psíquico, como a sensação de enclausuramento ${ }^{4}$, ou seja, de se sentir confinado, além de sentimentos de impotência, tristeza e desesperança ${ }^{10}$. Trabalhar cotidiana e continuadamente na prisão pode também acarretar esses sentimentos, na medida em que o contato prolongado é fator potencial de risco à saúde mental desses profissionais, alguns dos quais estão há mais tempo no ambiente prisional do que a maioria dos presos. Boa parte da execução penal não ultrapassa oito anos de encarceramento, sobretudo se considerada a progressão aos regimes semiaberto e aberto $^{5}$. Portanto, em alguma dimensão, todo aquele que orbita o contexto prisional experimenta a prisionização de forma viva, de acordo com aspectos subjetivos, sociais e situacionais frente à estrutura instável característica da prisão ${ }^{8}$.

Com um contexto ainda mais peculiar, os locais que aprisionam mulheres devem estar preparados para acolher especificidades da condição feminina, como o evento da maternidade. No estado de São Paulo, a Secretaria da Administração Penitenciária (SAP-SP) aloca mulheres no final da gestação em uma Unidade Materno-Infantil. Esse local, que conta com profissionais de saúde, acolhe gestantes e mães com bebês até o sexto mês de vida, a fim de receberem os cuidados necessários nessa fase ${ }^{11}$. Dessa forma, o cotidiano institucional dessas unidades propicia a convivência da ideologia prisional com a maternidade, fenômeno que faz emergir um campo de significativa complexidade pelas transformações vividas e por sua importância para o desenvolvimento do bebê. Assim, uma delicada situação para ambos, mãe e bebê, é configurada nesse ambiente, que é composto pela complexa interação entre a estrutura física que os acomoda, o contexto sociocultural pertencente à díade e os sujeitos no entorno dessa relação. Para um efetivo desenvolvimento da parceria mãe-bebê, é imprescindível que um ambiente de confiabilidade e o necessário ambiente de holding estejam disponíveis para a mãe, a fim de garantir a sustentação processual e repetitiva de cuidados à criança ${ }^{12,13}$. Nesse sentido, as mães necessitam de um ambiente com características semelhantes à função materna, isto é, um ambiente de cuidado e acolhimento, para que ela possa ficar disponível para o bebê. Todo esse processo de holding experienciado no início da vida perdura na continuidade do ser a partir das inter-relações que alimentam o indivíduo em toda a sua trajetória ${ }^{12}$. Ao considerar a importância das relações primárias do ser humano, reflete-se sobre o desafio desse evento fundante dentro da prisão, pois mães e bebês nesses espaços passam intensamente pela vivência da violência e pelas dificuldades e desafios de buscar significações para rupturas e carências ${ }^{14}$. Ademais, o holding deve estar presente na vida de todos os seres humanos, em especial nos contextos vulneráveis, como o da atuação dos profissionais em situação prisional.

Dessa maneira, as diferenças na atuação profissional nos presídios masculinos e femininos são ainda mais evidentes nos trabalhos desenvolvidos nas unidades materno-infantis, que formam um cenário paradoxal, composto por mães e bebês vinculados entre si, que parece destoar da atmosfera de punição e segregação que alimenta a prisão ${ }^{10}$. No entanto, há poucos estudos que abordam essas unidades e suas dinâmicas. 
Estar na rotina prisional possibilita exprimir sentimentos contraditórios, como hostilidade e carisma, força e amorosidade ${ }^{15}$, como também sentir-se próximo das presas, mas sempre acompanhado pela lógica prisional. Diante desses sentimentos ambivalentes, as unidades materno-infantis e seu entorno precisam contar com profissionais sensíveis às questões da maternidade, o que deve ser entendido como uma medida de ação em saúde, que, embora já seja assegurada por lei ${ }^{16}$, na prática nem sempre se efetiva. Contudo, essas ações são urgentes, pois quase $89 \%$ das presas estão em idade reprodutiva (entre 18 e 45 anos) e, em 2017, havia 84 bebês nas unidades prisionais administradas pela SAP-SP ${ }^{17}$.

Em meio a essa complexa e necessária temática, o objetivo deste artigo é identificar formas de pensar, sentir e agir de profissionais que trabalham em contexto prisional com prisioneiras gestantes e com bebês.

\section{Métodos}

\section{Referencial teórico-metodológico}

Trata-se de uma pesquisa qualitativa ${ }^{18}$, que utilizou como referência teórica especialmente dois autores, Winnicott ${ }^{19}$ e Krech et al. ${ }^{20}$. Cada um deles parte de uma base de interesse que lhe é própria - a vida psíquica em Winnicott e a vida social em Krech - e convergem para englobar em suas perspectivas iniciais os horizontes, respectivamente individual e coletivo, que cotejam as fronteiras de seus campos de interesse.

Winnicott construiu seu aporte teórico sustentando a importância do ambiente, inicialmente representado pela mãe ou cuidador, para a constituição do ser humano. $\mathrm{O}$ autor traz alguns conceitos importantes como a provisão ambiental, isto é, um ambiente favorecedor de sustentação física e emocional. O espaço potencial é a zona intermediária inicial entre mãe e bebê, que posteriormente se instala entre dois sujeitos disponíveis para tal relação espontânea, na qual tais sujeitos estabelecem relações e respectivas significações, o que possibilita o conhecimento, a valoração e a modulação das emoções em relação aos objetos do mundo ${ }^{19}$.

Por sua vez, a contribuição teórica de Krech et al. traz uma compreensão da dimensão social do ser humano. $\mathrm{O}$ autor afirma que o homem, em seu meio social, desenvolve formas de agir, de pensar e de sentir que são repetidamente expressas em sua história de vida e nas relações estabelecidas na sociedade a que ele pertence. O conjunto de crenças, sentimentos e formas de agir - que compõem a subjetividade - é nomeado como atitude ${ }^{20}$. A atitude, portanto, torna-se duradoura e com tendências a ser previsível e consistente, o que possibilita o convívio em sociedade.

\section{Local e sujeitos}

Participaram deste estudo oito profissionais que atuavam com prisioneiras gestantes e puérperas. Para escolha dos sujeitos, elegeu-se a técnica "bola de neve", processo em que um participante indica algum conhecido que pertença a um grupo social próprio ${ }^{21}$. A técnica "bola de neve" define o " $\mathrm{n}$ " de sujeitos com base no critério de saturação de conteúdos discursivos dos participantes e, neste caso, optou-se por definir um númerus cláusus baseado no critério de pertencimento às áreas em conexão institucional com essa população. A pesquisa ocorreu em 2015 com ex-servidores de unidades materno-infantis, não mais vinculados à SAP-SP, e com profissionais de outras instituições que atuavam indiretamente nas unidades materno-infantis: Defensoria Pública do Estado de São Paulo, Pastoral Carcerária, Departamento Penitenciário Nacional (DEPEN).

\section{Caracterização dos sujeitos}

As idades dos participantes, dois do sexo masculino e seis do sexo feminino, variavam entre 29 e 58 anos. Quanto à formação, metade era formada em Direito, dois, em Serviço Social e dois, em Psicologia, e todos tinham tempo de atuação na área de 1 a 20 anos. Cada profissional exercia uma atividade distinta. As atividades exercidas por cada um foram informadas por eles mesmos e descritas com o objetivo de identificar, na análise dos dados, a fala de cada área: Segurança: revistar, realizar escolta penitenciária, transportar o preso ou presa a outro presídio, fórum, hospital ou outro local designado, cuidando de sua segurança e da de todos os envolvidos; Saúde: oferecer uma atenção à saúde de qualidade aos presos, efetivar políticas e recomendações técnicas em saúde voltadas a toda a população prisional; Religião: falar sobre Deus e a Igreja Católica aos presos e acompanhar o cumprimento ou não dos direitos humanos; Jurídica: defender a presa da destituição familiar (mãe que perde a guarda da criança) e verificar a possibilidade de a criança ficar com a família extensa (avós, tios, primos); Política Estadual: acolher a demanda judicial na área criminal, fiscalizar as unidades prisionais; Formação em saúde: realizar grupos com as grávidas e mães presas com foco nos aspectos emocionais; Social: assessorar o fluxo informacional de mães presas e seus filhos, relacionar informações do processo criminal e do processo de infância, oferecer educação para presas e funcionários; e Política Nacional: formular políticas públicas voltadas às mulheres encarceradas, no âmbito nacional, articular ações junto ao Ministério da Justiça e às Secretarias das Administrações Penitenciárias Estaduais. 


\section{Instrumentos}

Foi aplicado um questionário elaborado pelos autores para caracterizar o perfil dos participantes, com as seguintes variáveis: formação, função, idade, tempo na função junto às grávidas e presas com bebês. Foi efetuada uma entrevista piloto, ou seja, um ensaio prévio com poucas réplicas, para eventuais adaptações e ajustes da técnica ${ }^{22}$, realizada com uma ex-servidora que atuava na gestão em saúde da SAP. Posteriormente, foi realizada entrevista individual semidirigida. As falas foram gravadas e transcritas. O aporte teórico da entrevista semidirigida teve como base o conceito de atitude ${ }^{20}$, que é categorizada em três componentes interdependentes: os aspectos cognitivos, os emocionais e as tendências à ação. Para apreender os aspectos cognitivos (pensamentos, conhecimentos, crenças), as perguntas das questões eram iniciadas com “Qual sua opinião?”. Já as questões relacionadas aos aspectos emocionais iniciavam-se com: "Que tipo de emoções e sentimentos (positivos ou negativos) são despertados em você?”. Por fim, para o terceiro componente da atitude, a tendência à ação, buscou-se perguntar sobre formas de agir diante das situações da atuação. Houve o esforço de dividir o pensar, o sentir e o agir para compreender e não para reduzir a complexidade de tais componentes subjetivos ${ }^{20}$.

\section{Procedimentos}

A coleta dos dados ocorreu no período de janeiro a fevereiro de 2015. É importante citar a dificuldade em estabelecer contato com os profissionais da prisão. Mesmo que a técnica bola de neve tenha potencializado a indicação de algum colega disponível, percebemos que havia um muro simbólico que prendia o profissional ao receio de aceitar participar ou, se aceitava, tinha receio de falar, possivelmente pelos reflexos da vigilância e do isolamento prisional. O primeiro convidado foi um profissional que atendia ao critério de inclusão, participante de um curso ministrado pela instituição dos pesquisadores. Em sua entrevista, foi pedido que indicasse outro profissional com o perfil necessário. Caso a pessoa indicada não desejasse participar, o profissional participante indicava outro colega. A pesquisa de campo se deu em local pré-agendado com cada participante, com a leitura e assinatura do termo de consentimento e a aplicação dos instrumentos, sob autorização de gravar todo o encontro. Buscou-se criar um ambiente acolhedor, sem julgamentos, sustentado pelos preceitos de Winnicott ${ }^{19}$, que defende que um encontro com potência para expressão da subjetividade depende da confiabilidade e da disponibilidade dos sujeitos do encontro.

\section{Análise de dados}

Os dados coletados foram submetidos à análise de conteúdo na modalidade temática ${ }^{23-25}$. A análise temática é composta pelas fases de: pré-exploração ou leituras flutuantes do material; seleção das unidades de análise; e categorização e subcategorização ${ }^{26}$.

\section{Aspectos éticos}

O projeto de pesquisa foi aprovado pelo Comitê de Ética da Faculdade de Saúde Pública da Universidade de São Paulo, em 23 de maio de 2014, sob parecer $n^{\circ} 654.001$.

\section{Resultados e discussão}

Ao assumir uma função ocupacional, o profissional se implica subjetivamente por meio de suas atitudes, construídas a partir das relações sociais e compostas por suas crenças, pensamentos, fantasias e referências produtoras das ações ocupacionais e das transformações em sua subjetividade ${ }^{20}$. Em contexto prisional, as atitudes dos profissionais são marcadas pela percepção de que há avanços e retrocessos cotidianos que despertam sentimentos de potência e impotência vividos de forma mais intensa do que em outros locais. Os entraves, como morosidade administrativa e judicial, inflexibilidade de regras, pouca coesão da equipe e ambiente vulnerável, aprisionam e refletem nas suas atitudes, conforme trechos de falas reproduzidos a seguir:

As soluções não são fáceis de serem encontradas
por vários aspectos, o mais simples deles é a própria
burocracia estatal, de você ter que licitar, arrumar a
liberação das verbas, tudo isso exige não só tempo
como também técnicos especializados para escrever
os projetos e tal. (Saúde)

Esses entraves denunciam profundos conflitos ${ }^{27}$ expressos pelos sentimentos de enclausuramento ${ }^{4} \mathrm{e}$ de vulnerabilidade "inerentes às características do trabalho no cárcere” (p. 15) ${ }^{5}$, devido à dinâmica de constantes vigilância e periculosidade. Além desse sofrimento decorrente dos efeitos prisionais, sentimentos de impotência, tristeza e de pouca esperança também são vivenciados diante das dificuldades de efetivações nas ações do trabalho. Assim, a impotência culmina no enclausuramento não só subjetivo, como também dos processos de trabalho, ou seja, as atitudes são confinadas segundo a lógica prisional. Esses sentimentos acompanham pensamentos desmotivadores, como o desejo de desistir e a falta de vontade, que acarretam conformismo com a rotina e poucas ações para romper ou lutar contra esses obstáculos. Por outro lado, tais entraves são oportunidades 
de surgimento de potenciais espaços de reflexões e novas possibilidades de sentidos frente a situações de sofrimento ${ }^{28}$. Neste trabalho, ações potentes são permeadas por criatividade, porque as frustrações podem, também, gerar atitudes criativas no sentido de suportá-las e reconhecer limites subjetivos e sociais ${ }^{13}$, como aponta a fala de uma profissional:

No final do trabalho com grupos de grávidas apareceu o bebê [risos], conseguimos fazer alguns registros, carta pro bebê, pensar num mapeamento de vínculos, com quem esse bebê ia ficar depois, a gente conseguiu pensar em possibilidades nos últimos meses do trabalho, foi legal. Mas tem um sistema na prisão que é muito poderoso assim, era um trabalho que não tinha muito valor, não para as mulheres, mas 'tô' falando dos poderes ali, nem a polícia nem o [facção criminosa] facilitavam nosso trabalho. (Formação Saúde)

A criatividade expressa nas propostas de grupos terapêuticos com as gestantes presas ocorria no sentido de criar um espaço para que elas simbolizassem e se implicassem subjetivamente, além de ofertar um holding às mães e as acolher. Dessa forma, ações criativas promovem encontros genuínos e estimuladores de amadurecimento emocional $^{19}$. Diante da atitude de lutar contra o instituído, vivenciar uma situação de alto impacto emocional e refletir sobre ela pode contribuir para a criação de novas formas de pensar, de sentir e de agir frente ao contexto. Um exemplo disso é o oferecimento de novas atividades, mesmo com os obstáculos e suas repercussões emocionais relatadas, como impotência e desânimo, que se manifestam porque uma ação criativa, que preconize a subjetividade dos envolvidos, pode ser vista como obstáculo ao cumprimento da lógica instituinte:

\begin{abstract}
Teve um momento que nós escrevemos uma carta para a diretoria, com todas as reivindicações até para dar uma esvaziada nessa questão da elaboração de "tá" na prisão e tal, então vamos escrever uma carta, já que tem tanta "queixação", mas foi barrada pelo [facção criminosa]. No grupo [psicoterápico, semanal às presas] seguinte foram pouquíssimas pessoas e quem foi falou que não era para escrever carta nenhuma. Então tem um sistema na prisão que é muito poderoso assim. (Formação Saúde)
\end{abstract}

A profissional cujo relato foi apresentado acima avaliou como produtivo documentar as reivindicações, para extravasar as angústias das presas participantes do grupo. No entanto, outras instâncias além das institucionais, como facções criminosas, exerciam influências nos assuntos e na organização prisional, o que acarretava o abafamento de movimentos que destoavam dos preconizados. Nesse sentido, o sofrimento psíquico se expressa para além de um efeito do trabalho, pois revela ser o próprio instrumento que produz esse trabalho ${ }^{29}$, como ilustra a fala a seguir, que evidencia um sentir e, consequentemente, um agir ocupacional:

[...] é triste que tem meninas de vinte e poucos anos que não sabem escrever, às vezes você dá a folha de canto e ela fala "ah, não sei ler", mas assim é a palavra de Deus, é essa troca, daí eu tento superar isso, tento me aproximar, ajudo ela a ler ou puxo conversa, como é que tá, como foi sua vida, sua família, é essa relação mesmo de confiança e de me virar na dificuldade. (Religião)

Dessa forma, tristeza e falta de esperança, sentimentos que minam os comportamentos promotores de uma postura ativa, coexistem com pensamentos de esperança a favor do enfrentamento das impotências. Assim, de acordo com os profissionais participantes, a potência emerge nos momentos das reuniões multiprofissionais em que há reflexão crítica partilhada, nos grupos criados com as presas sobre amamentação, direitos e religiosidade, dentre outras ações. Essas situações de atitudes diante das impotências podem representar alívio do sofrimento, pois, se houver recursos emocionais para superá-las, possibilitam o amadurecimento e novas formas de relacionar-se com o ambiente ${ }^{13}$. Assim, nesse contexto com variados entraves, os profissionais reconhecem que há também um valor na função que exercem e buscam significados como potência nas ações que puderam construir:

O pouco que a gente faz é de suma importância né... (Religião)

Acho que o trabalho foi rico, mesmo com vários atravessamentos. (Formação em Saúde)

No cotidiano constituído pelas potencialidades e impotências, acompanhadas da expressão e ressignificação das atitudes dos profissionais, os resultados das vivências não podem ser reduzidos à classificação binária de ser potente ou não. Isso porque os profissionais se sentem satisfeitos quando há um esforço conjunto em um processo de tentativas que partam de forças interdisciplinares e interinstitucionais em prol de um objetivo em comum, de acordo com a fala:

[...] na equipe tanto de Segurança, de Saúde, Administrativa, existem profissionais que se unem para resolver as questões em situações drásticas (...) nas dificuldades impactantes e monstruosas você tem que ter visão para ir em busca de soluções, soluções é [sic]: não tem espaço adequado, vamos fazer projeto, ver custo; não tem profissionais adequados, vamos dar capacitação; o que precisa e o que é positivo é isso, ter uma pessoa com visão macro da saúde pública e que possa encontrar parcerias, fazer articulações, buscar teorias. (Saúde)

A mobilização realizada de forma grupal se mostra mais eficiente no manejo frente às adversidades e 
aos contornos operacionais. Quando há situações de crise vividas conjuntamente, há maior possibilidade de novos rearranjos que são compartilhados também coletivamente, fenômeno potente porque promove o enriquecimento das relações estabelecidas em dado tecido social ${ }^{28}$. Assim, favorece-se o holding que sustenta os profissionais e suas práticas mais próximas e alinhadas. Uma situação que, em geral, promove ações conjuntas é a tentativa de soltura da presa gestante ou lactante. Boa parte dos profissionais que desejam a soltura de uma presa nessas condições é movida por pensamentos em prol dos direitos humanos, por empatia e por sentimentos de amor ao próximo. Esse desejo se expressa em atitudes criativas de diversas áreas, como a esfera jurídica, que se manifesta por meio da difusão de informações sobre direitos em cartilhas, da elaboração de políticas, de visitas às prisões para fiscalização e verificação do exercício dos direitos das presas, e até por meio de pedidos diretos de pena alternativa ao juiz (como prisão domiciliar). Essa situação, além de outras com desfechos satisfatórios, despertam grande emoção e sensação de realização:

Eu acho que eu já sou um poço de sentimentos nesse sentido [...] cada soltura [de gestante] que a gente consegue a gente comemora de se abraçar mesmo e pular, então é totalmente um momento feliz mesmo de conseguir. (Social)

No começo foi sentimento de espanto assim, de estranhamento, uma coisa estranha, você se impacta de ver bebê na prisão, até quer negar. No outro é um sentimento de uma magnitude que você pode fazer a diferença, você se sentia até gratificada que você conseguiu fazer algo que pode fazer essa diferença para as crianças, para os técnicos, não é a salvação do mundo, mas fez alguma diferença, então esse sentimento é bom, é positivo. (Saúde)

Os sentimentos expressos pelos profissionais parecem revelar a ambiguidade da potência-impotência vivida em seu cotidiano, marcado por emoções que ora os enobrecem, ora os desmotivam. Embora a atitude na fase adulta possua tendência estável e relativamente previsível, ela não é estática ${ }^{20}$. Dessa forma, a prática provoca sentimentos intensos que dependem de como as experiências afetam os profissionais, o que demonstra uma especificidade da intensidade da ambivalência, possivelmente pelo contexto vulnerável que caracteriza a prisão. Assim, a potência e suas emoções, acompanhadas da impotência e de seus reflexos psíquicos, são vividas concomitantemente, como podemos observar em mais uma fala abaixo:

[...] fiquei revoltada com as condições horríveis, lugar feio, mulheres sendo maltratadas, sabe? Condições nada dignas, assim, para o ser humano, sabe? Mas foi um trabalho que me gratificou [...] senti que pude ajudá-las [refere-se ao grupo psicoterápico semanal com gestantes e mães lactantes]. (Formação Saúde)

Mesmo na adversidade ocupacional, os profissionais mantêm o desejo de promover ações que minimizem a ambiguidade, mas essa condição inerente é às instituições totais. Especificamente quanto ao trabalho com a segurança, a contradição é percebida nas funções básicas do cargo: ressocializar e controlar. Tais atividades exigem um posicionamento dos profissionais, expresso nos sentimentos de raiva e carinho, como aponta o estudo de Barcinski et al. ${ }^{27}$. As autoras também refletem sobre a coexistência desses sentimentos, frutos da reprodução de um lugar igualmente contraditório de ressocialização e punição. Ao constatar essa perspectiva da contradição e a intensidade das vivências diárias desses profissionais, consideramos que a opção por trabalhar nesse local vai além da busca da estabilidade financeira, em casos de servidores públicos ${ }^{4,30}$. Assim, as funções são cumpridas e sustentadas pelas expectativas da função assumida (nas descrições de atividades atribuídas ao cargo), mas também por ideologias e crenças desses profissionais:

A questão do número reduzido de mulheres até dificulta isso, a questão de gênero, de não achar que é importante [...] eu sou uma feminista, obviamente, então a gente luta pela visibilidade, para entender que há diversas violências aí, simbólicas, envolvidas com esse tema e que tem que tornar ele mais à tona né, colocar ele mais na agenda pública, digamos assim. (Política Nacional)

A projeção de desejos no trabalho mostra o lugar emocional e social da ocupação nas vidas dos profissionais. O trabalho abre possibilidades de estímulo e orientação do pensamento humano, além de delinear o comportamento individual e social e representar o motor essencial do progresso e da dignidade ${ }^{31}$. O trabalho assume centralidade porque atua em profunda função subjetiva e social, já que sua forma se inscreve na subjetividade do trabalhador e na subjetividade coletiva de um grupo ocupacional, de modo que permite construções de sentidos e mostra-se ser, ao mesmo tempo, gerador de sofrimento e potencializador de criatividade ${ }^{29}$.

Nessa atuação com presas mães, coexistem representações de cada profissional do que é ser mãe, ser mulher e ter um bebê além (ou apesar) de ter cometido um crime. Há um transbordar de simbolizações sobre esse cenário, sobre cada mulher que habita esse local, que inevitavelmente os invocam a pensar e revisitar suas representações e sentimentos despertados por elas, além de conduzir a forma de agir diante desse contexto. Os discursos demonstram um reflexo das ideias dos locais que atuam e das funções que exercem. Essas aproximações entre as falas, as funções e os locais de pertencimento podem ser 
observadas, por exemplo, nos discursos dos profissionais da Segurança, discursos que são consoantes a sua conduta laboral de controle. Outrossim, na Defensoria Pública e na Pastoral Carcerária, os profissionais defendem a mesma ideia que rege essas instituições: a efetivação dos Direitos Humanos. Essa sintonia demonstra que as histórias de vida dos profissionais, como esses sujeitos se constituem e os sentidos atribuídos às experiências pessoais, dialogam entre si, norteiam sua conduta e vão ao encontro dos profissionais ${ }^{32}$. Desse modo, o sujeito sempre está situado em relação a algo, como a outro sujeito ou à política, à religião, à arte e às demais heranças culturais da sociedade que influenciam sua atitude ${ }^{20}$. Nesse sentido, ter uma função ocupacional, em geral, revela e esconde a estratégia de pensamento que a funda, que a tece ${ }^{33}$. Quando há a realização ou a tentativa de parcialmente realizar os desejos pessoais, ou ainda a possibilidade de manifestar gostos e interesses no ambiente de trabalho, viabiliza-se o exercício de sua função sem excesso de sofrimento psíquico que o imobilize ${ }^{32}$. Significativamente, o trabalho mobiliza desejos de contraposição e desperta a energia diária de luta apoiada nos sentimentos, nos pensamentos e nas formas de agir dos profissionais:

Então tem uma série de vulnerabilidades que agravam a situação, então a gente luta aí para que essas vulnerabilidades não sejam tão agravantes. (Política Nacional)

Cada vez que a gente consegue a soltura de uma mulher, é uma luta... A nossa maior luta é essa, conseguir [...] a unidade prisional não é um local adequado para criança e nem para mãe, nem para o homem, nem para ninguém [...] é uma questão pessoal que não sei de onde vem na verdade. Eu nasci, fui criada, cresci em periferia, nunca passei fome, mas passei vontade, e fui atrás de empregos para conseguir minha faculdade, e as pessoas que eram traficantes, daquela época, eram nossos amigos, que cresceram comigo, então acho que pode ser isso que tenha facilitado que eu os enxergue como iguais. (Social)

As narrativas são marcadas por luta e por humanização no local e trazem ideias de outras possibilidades de manejo mais humanizado frente à maternidade na prisão atual. Apesar de o profissional da Segurança também reconhecer essa emergência de mudanças, seu pensamento ainda carrega a lógica institucional de controle e a defesa das práticas de vigilância e de tendência ao fechamento ${ }^{34}$ :

Tem um modelo russo ou francês de penitenciária para gestantes e pós-natal, é um período maior junto, não tem uma imagem carcerária, lógico que no perímetro tem toda a segurança, os muros altos, mas você vê como uma chácara, um spa, é um modelo real de ressocialização, seria legal se eles fizessem isso. (Segurança)

Embora mencione uma alternativa de encarceramento, seu discurso traz as marcas da disciplina e do controle, aspectos presentes e prementes em sua atividade profissional. Demonstra-se, assim, a presença dos sentimentos contraditórios como hostilidade e carisma, força e amorosidade ${ }^{15}$, presentes nos profissionais em contexto prisional. Nas Unidades Materno-infantis tal contradição aparentemente se potencializa: sentimentos, pensamentos e ações conflituosas emergem em variadas situações. A amorosidade, por exemplo, encoraja a profissional a buscar informações sobre família ou o processo da presa, atitude concomitante à hostilidade de outro profissional da Segurança. Movido pela ideia de que "está presa porque mereceu”, ele não fala sobre sentimentos, pois afirma que em seu trabalho não se deve sentir, e não responde a uma prisioneira ao ser indagado se possui filhos. Essas contradições geram repercussões emocionais como defesas empregadas por esses profissionais. A fim de ocultar um sofrimento, um mecanismo de defesa grupal é acionado quando não há espaço para expressão de conflitos intrapsíquicos, o que culmina em arranjos institucionais inflexíveis ${ }^{29}$. Diante de um ambiente ocupacional rígido, as atitudes alimentam e retroalimentam as experiências profissionais.

Tal perspectiva converge para outros estudos sobre agentes penitenciários ${ }^{30,35}$. As vivências pessoais dos profissionais da Segurança influenciam nas decisões tomadas no cotidiano prisional, algumas voltadas para o afrouxamento da dinâmica prisional e outras para decisões que a reafirmam. Seu discurso trouxe constantemente essa binaridade compaixão-punição motivada por justiça:

[...] se você for ver só pela pessoa, é ruim, é horrível. Mas o que ela fez lá atrás que causou essa consequência? Você acaba mesclando isso daí. (Segurança)

Em um momento quando a compaixão se sobressai, além do desejo por condições dignas previstas pela legislação, ele afirma que:

\section{[...] se você for olhar na lógica da superlotação que tá, você pega, você abre o portão e deixa todo mundo sair até chegar no número ideal, entendeu? (Segurança)}

Em meio aos discursos e aos reflexos da dinâmica prisional, os profissionais necessitam de uma rede de sustentações extramuros, como os apoios emocional, familiar, espiritual e teórico-educacional:

[...] você ter uma estrutura por trás de tudo isso, religiosa, familiar, cultural, com certeza você vai levar tudo isso e também você busca mais conhecimento depois que você está lá dentro (...) Acredito eu que, se você não tiver apoio, você não consegue tocar o teu trabalho para frente. Com certeza tenho esse apoio sim e vou chegar em casa tranquilo, né? Isso que eu sempre tento 'tá' buscando, essa minha estrutura. (Segurança) 
O holding que sustenta esses profissionais, portanto, depende das trocas nos diversos contextos a que eles pertencem. Compartilhar, então, é um ato de cuidado entre os profissionais, expresso em decisões consensuais, e favorece as relações empáticas:

Acho que a gente tem o apoio profissional, técnico, dentro da Defensoria temos a equipe de psicólogo, assistente social, junto com o defensor tem esse atendimento interdisciplinar, é esse momento que tem apoio, de outros saberes, de outras áreas. (Jurídica)

A fala acima indica a importância da interdisciplinaridade como suporte para as dificuldades diárias. Com base nisso, é compreensível perceber que as especificidades nas falas dos profissionais são frutos ou consequências de suas áreas de atuação e de seus valores pessoais. As atitudes dos profissionais, portanto, levam-nos a traçar sua trajetória profissional e sua forma de atuação no cotidiano prisional: alguns reproduzem a lógica do encarceramento, outros são movidos pela busca de feixes que possibilitem porosidades no muro-controle da prisão.

\section{Considerações finais}

Consideradas as grandes diferenças entre os grupos sociais em questão, tanto os presos quanto os profissionais pertencem à prisão e nela vivem cotidianamente, além de sentirem os efeitos do encarceramento. Os profissionais participantes desta pesquisa revelaram grandes adversidades vivenciadas no dia a dia, como burocracias administrativas, morosidade jurídica e escassez de recursos humanos, físicos e financeiros, somadas ao emaranhado de vulnerabilidades sociais em que essas mulheres, mães presas, se encontram. Há, também, a esperança em superar tais dificuldades por meio dos espaços de reflexão e de acolhimento das demandas emocionais das presas no evento da maternidade, das possíveis solturas e alternativas de punições, do oferecimento de visitas religiosas e das informações sobre seu processo criminal e sobre sua família, dentre outras ações. Em meio ao convívio da potência-impotência, os sentimentos dos profissionais são intensos, de alegria e de tristeza, coexistentes em toda a prática. Sejam sentimentos ou decisões, todos os enfrentamentos e impedimentos, quando compartilhados coletivamente, são ressignificados e tornam-se promotores de novas reconfigurações de trabalho e edificadores da atuação interdisciplinar.

Em meio a esse cenário, as potencialidades e impotências, presentes em qualquer local de trabalho, têm especificidade nesse local, pois refletem e legitimam a rigidez da lógica prisional. Assim, para executar seu trabalho, movidos por desejos e demandas subjetivos, em oposição à organização de controle e à inflexibilidade, os profissionais tentam constantemente alinhar as regras da realidade institucional com as atitudes e os sentidos que nutrem e sustentam sua atuação. Contudo, todas as ações e sentimentos de esperança e desesperança modelam as atitudes dos profissionais de variadas áreas que se encontram aprisionados pela lógica penitenciária. É recorrente que a prisão não possibilite ações de expressão da subjetividade de forma mais espontânea, criativa, que permitam outras reconfigurações psíquicas e sociais. Algumas reflexões foram propostas neste artigo na tentativa de compreender as atitudes dos profissionais para além de um campo enredado por regras e seus efeitos. Outras reflexões são relevantes, como pesquisas com enfoque nas questões éticas, suas repercussões no manejo da criatividade e das defesas desses profissionais, além de outras voltadas à saúde mental no trabalho em contexto prisional.

\section{Contribuições de autoria}

Pereira TG, Reis AOA e Zioni F tiveram contribuição substancial na concepção do estudo, no levantamento, análise e interpretação dos dados, na elaboração e revisões críticas do manuscrito e na aprovação da versão final publicada. Todos os autores assumem responsabilidade pública integral pelo trabalho realizado e pelo conteúdo aqui publicado.

\section{Referências}

1. Poehlmann J. Children's Family Environments and Intellectual Outcomes During Maternal Incarceration. J Marriage Fam. 2005;67(5):1275-85.

2. Departamento Penitenciário Nacional (BR). Levantamento Nacional de Informações Penitenciárias INFOPEN - junho de 2014. Brasília, DF: Ministério da Justiça, Departamento Penitenciário Nacional; 2015.
3. Walmsley R. World Pre-trial/Remand Imprisonment List [Internet]. 4th ed. London: Institute for Crime \& Justice Policy Research; 2017 [citado em 19 abr 2019]. Disponível em: https://www.prisonstudies. org/sites/default/files/resources/downloads/world_ pre-trial_list_4th_edn_final.pdf

4. Rumin CR. Sofrimento na vigilância prisional: o trabalho e a atenção em saúde mental. Psicol Cienc Prof. 2006;26(4):570-81. 
5. Lourenço LC. Batendo a tranca: Impactos do encarceramento em agentes penitenciários da Região Metropolitana de Belo Horizonte. Dilemas. 2010;3(10):11-31.

6. Godoi R. O sistema prisional e seus agentes mediadores: uma proposta metodológica exploratória. Anais do XV Congresso Brasileiro de Sociologia; 26-29 jul 2011; Curitiba, Brasil. Curitiba: Sociedade Brasileira de Sociologia; 2011.

7. Godoi R. Ao redor e através da prisão: cartografias do dispositivo carcerário contemporâneo [dissertação]. São Paulo: Universidade de São Paulo; 2010.

8. Clemmer D. The Prison Community. 2nd ed. New York: Holt, Rinehart and Winston; 1958.

9. Monteiro LEC. A Reinserção Social dos Reclusos da Cadeia Central da Praia [monografia]. Cidade da Praia: Universidade Jean Piaget de Cabo Verde; 2007.

10. Pereira TG. Atitudes e intervenções de profissionais que atuam junto a mulheres grávidas ou com bebês em contexto prisional [dissertação]. São Paulo: Universidade de São Paulo; 2015.

11. São Paulo (Estado), Secretaria da Administração Penitenciária. Cartilha do leite materno [Internet]. São Paulo: Secretaria da Administração Penitenciária; 2008 [citado em 19 abr 2019]. Disponível em: http://www.sap.sp.gov.br/ download files/pdf files/cartilha/ 2008.pdf

12. Winnicott DW. Tudo começa em casa. 3a ed. São Paulo: Martins Fontes; 1999.

13. Winnicott DW. A experiência mãe-bebê de mutualidade. In: Winnicott C, Shepherd R, Davis M, organizadores. Explorações psicanalíticas. Porto Alegre: Artes Médicas Sul; 1994. p. 195-202.

14. Marin ISK. Tornar-se mãe num presídio: a criação de um espaço potencial. In: Reis AOA. Maternidade e Sistema Prisional. São Paulo: Schoba; 2014. p. 25-49.

15. Amador FS. Entre prisões da imagem, imagens da prisão: um dispositivo tecno-poético para uma clínica do trabalho [tese]. Porto Alegre: Universidade Federal do Rio Grande do Sul; 2009.

16. Brasil. Lei $\mathrm{n}^{\mathrm{o}} 11.942$, de 28 de maio de 2009. Nova redação aos arts. 14, 83 e 89 da Lei $\mathrm{n}^{0} 7.210$, de 11 de julho de 1984 - Lei de Execução Penal, para assegurar às mães presas e aos recém-nascidos condições mínimas de assistência. Diário Oficial da União. 29 maio 2009:1.

17. Departamento Penitenciário Nacional (BR). Levantamento nacional de informações penitenciárias - INFOPEN. 2a ed. Brasília, DF: Ministério da Justiça e Segurança Pública; 2017.

18. Medeiros M, Munari DB, Bezerra ALQ, Barbosa MA. Pesquisa Qualitativa em Saúde: implicações éticas.
In: Guilhem D, Zicker F, editores. Ética na pesquisa em saúde: avanços e desafios. Brasília, DF: UnB; 2007. p. 99-118.

19. Winnicott DW. O brincar e a realidade. Rio de Janeiro: Imago; 1975.

20. Krech D, Crutchfield RS, Ballachey EL. Individual in Society: a textbook of social psychology. New York: McGraw-Hill; 1962.

21. Polgar S, Thomas SA. Introduction to research in the health sciences. 6th ed. London: Churchill Livingstone; 2013.

22. Volpato GL. Ciência: da filosofia à publicação. São Paulo: Cultura Acadêmica; 2013.

23. Minayo MCS. O desafio do conhecimento: pesquisa qualitativa em saúde. 4a ed. São Paulo: Hucitec; 1996.

24. Moraes R. Análise de conteúdo. Educacao. 1999;22(37):7-32.

25. Bardin L. Análise de conteúdo. Reto LA, Pinheiro A, tradutores. São Paulo: Edições 70; 1979.

26. Campos CJG. Método de análise de conteúdo: ferramenta para a análise de dados qualitativos no campo da saúde. Rev Bras Enferm. 2004;57(5):611-4.

27. Barcinski M, Altenbernd B, Campani C. Entre cuidar e vigiar: ambiguidades e contradições no discurso de uma agente penitenciária. Cien Saude Colet. 2014;19(7):2245-54.

28. Sanches RM, organizador. Winnicott na clínica e na instituição. São Paulo: Escuta; 2005.

29. Dejours C. A loucura do trabalho: estudo de psicopatologia do trabalho. 5a ed. São Paulo: Cortez; 1992.

30. Taets ARF. Abrindo e fechando celas: narrativas, experiências e identidades de agentes de segurança penitenciária femininas [dissertação]. São Paulo: Universidade de São Paulo; 2012.

31. Freinet C. A Educação do Trabalho. São Paulo: Martins Fontes; 1998.

32. Muylaert CJ. Formação, vida profissional e subjetividade: narrativas de trabalhadores de Centro de Atenção Psicossocial Infanto juvenil [dissertação]. São Paulo: Universidade de São Paulo; 2013.

33. Guirado M. A análise institucional do discurso como analítica de subjetividade [tese]. São Paulo: Universidade de São Paulo; 2009.

34. Goffman E. Manicômios, Prisões e Conventos. São Paulo: Perspectiva; 1961.

35. Lourenço LC. Batendo a tranca: Impactos do encarceramento em agentes penitenciários da Região Metropolitana de Belo Horizonte. Dilemas. 2010;3(10):11-31. 